\title{
ESTADOS E OS NOVOS AMBIENTES TRANSNACIONAIS ${ }^{1}$
}

\section{STATES AND NEW TRANSACTIONAL ENVIRONMENTS}

\author{
PAULO MÁRCIO CRUZ ${ }^{2}$ \\ MAIKON CRISTIANO GLASENAPP ${ }^{3}$
}

\begin{abstract}
RESUMO: A transnacionalidade faz parte de uma família contemporânea de categorias, que representam um novo contexto mundial, surgido principalmente da intensificação de natureza econômica-comercial no período pós-queda do socialismo. Nesse sentindo, este artigo procura apresentar reflexões sobre as ações que se realizam além das fronteiras nacionais. Igualmente, apresenta reflexões sobre os efeitos da globalização, que teoricamente estão em novos ambientes transnacionais, que não são nacionais nem internacionais.

PALAVRAS-CHAVE: Estado; Globalização; Transnacionalidade.
\end{abstract}

ABSTRACT: Transnationality is part of a contemporary family of categories that represent a new global context, which emerged mainly from the intensification of an economic and commercial nature in the period following the fall of socialism. This article therefore presents reflections on the actions that are carried out beyond the national boundaries. It also presents reflections on the effects of globalization, which are theoretically in new transnational environments that are neither national nor international.

KEYWORDS: State; Globalization; Transnationality.

Artigo recebido em 01.04.2015. Pareceres emitidos em 25.05.2015 e 29.05.2015.

Artigo aceito para publicação em 30.06.2015.

${ }^{1}$ Artigo elaborado durante Estágio Sênior com bolsa CAPES do Prof. Dr. Paulo Márcio Cruz, na Universidade de Alicante, Espanha, realizado de 02 de agosto de 2014 a 30 de abril de 2015.

${ }^{2}$ Pós-Doutor em Direito do Estado pela Universidade de Alicante, na Espanha, Doutor em Direito do Estado pela Universidade Federal de Santa Catarina e Mestre em Instituições Jurídico-Políticas também pela Universidade Federal de Santa Catarina - UFSC. Coordenador e Professor do Programa de Pós-Graduação Stricto Sensu em Ciência Jurídica da Universidade do Vale do Itajaí - UNIVALI em seus cursos de Doutorado e Mestrado em Ciência Jurídica. Ex-Secretário de Estado em Santa Catarina e Vice-reitor da UNIVALI. Professor visitante nas Universidades de Alicante, na Espanha, e de Perugia, na Itália.pcruz@univali.br

${ }^{3}$ Realizando Estágio de Pós-doutoramento pelo Programa de Pós-graduação em Direito da Universidade Federal de Santa Catarina - UFSC; Doutor e Mestre em Ciência Jurídica pela Universidade do Vale do Itajaí - UNIVALI; Professor e Coordenador dos Cursos de Graduação e Especialização lato sensu em Direito do Centro Universitário - Católica de Santa Catarina das unidades de Jaraguá do Sul e Joinville.maikon@catolicasc.org.br 
SUMÁRIO: Introdução; 1. Estado Moderno; 1.1 Estado Moderno e a Soberania; 1.1.1 Soberania: qualidade do poder soberano; 1.1.2 A Relativização da Soberania; 2. Estado Constitucional Moderno em Crise; 2.1 A Decadência (crise) da Autoridade Estatal e a Crescente Interconexão Mundial; 3. O Fenômeno das Globalizações; 3.1 Globalizações: econômica, social e política; 4. Os Novos Ambientes Assimétricos Transcionalizados; Considerações Finais; Referências Bibliográficas.

SUMMARY: Introduction; 1. Modern State; 1.1 Modern State and Sovereignty; 1.1.1 Sovereignty: quality of sovereign power; 1.1.2 The Relativization of Sovereignty; 2. Modern Constitutional State in Crisis; 2.1 The Decadence (crisis) of the State Authority and the Growing Global Interconnection; 3. The Phenomenon of Globalizations; 3.1 Globalizations: economic, social and political; 4. The New Assymetrical Transnationalized Environments; Final Considerations; Bibliographic References.

\section{INTRODUÇÃO}

O Estado não despareceu, mas relativizou-se em determinadas dimensões legais, de maneira que não se reconhece mais o ente político-jurídico em suas características clássicas ${ }^{4}$.

Os novos ambientes transnacionais da atualidade caracterizados por meio da complexa teia de relações (globalizadas) políticas, socias, econômicas e jurídicas fazem emergir novos atores, interesses e conflitos.

A formação dos novos poderes transnacionais, possibilitados pela globalização que estão sem regulamentação, requer a politização da discussão sobre a limitação desses tipos de poder e, por conseguinte, a criação de direitos (transnacionais) destinados a regulá-los e limitá-los.

As novas demandas transnacionais e os novos ambientes assimétricos caracterizam a emergência de novos cenários e novas instituições políticasjurídicas (transnacionais) que devem possibilitar a politização das discussões como resposta a globalização e suas consequências.

Portanto, este artigo apresenta uma reflexão teórica sobre os novos ambientes de contexto transnacional, brotados da intensificação das operações de natureza econômica-comercial no período do pós-guerra, que para Joana Stelzer ${ }^{5}$ se caracteriza "[...] pela desterritorialização, expansão capitalista, enfraquecimento da soberania e emergência de ordenamento jurídico gerado à margem do monopólio estatal".

O referente da pesquisa se justifica no esforço teórico para desenvolver a possibilidade de construção de novos espaços (esferas) democráticos de governança e regulação transnacionais (para além do Estado Constitucional Moderno e das relações internacionais, decorrentes da interdependência dos

\footnotetext{
${ }^{4}$ STELZER, Joana. O Fenômeno da Transnacionalização de Dimensão Jurídica. In: CRUZ, Paulo Márcio; STELZER, Joana. (orgs.). Direito de Transnacionalidade. Curitiba: Juruá, 2009. p. 16.

${ }^{5}$ STELZER, Joana. O Fenômeno da Transnacionalização de Dimensão Jurídica. In: CRUZ, Paulo Márcio; STELZER, Joana. (orgs.). Direito de Transnacionalidade. Curitiba: Juruá, 2009. p. 16.
} 
Estados), que tenderia a orientar a vida dos novos/velhos atores e dos novos poderes globais na nova ordem transnacional - novos ambientes transnacionais.

\section{ESTADO MODERNO}

A compreensão social e o modelo político moderno pensado a partir de uma estrutura mecânica de organização e detenção do poder transformou o Estado em uma organização social, econômica e política, na qual os indivíduos desempenham funções "estabelecidas" em grupos contratuais ${ }^{6}$.

Essa moderna estrutura de organização contratual da sociedade resignificou a produção do poder e do direito para a dimensão territorial, substituindo as débeis alianças corporativas da sociedade pré-moderna (medieval) pela coesão solidária dos cidadãos ${ }^{7}$.

O Estado-nação passar a existir como um conjunto de formas institucionais de governo que mantem o monopólio administrativo sobre um território (com limites definidos - as fronteiras), consagrando sua denominação por lei e pelo controle direto dos instrumentos da violência interior e exterior.

Nesse sentido, o Estado moderno é aqui entendido como aquele tipo de organização política surgida das revoluções burguesas e norte-americana dos séculos XVIII e XIX. Portanto, o arquétipo político da modernidade são modelos de Estados-nação soberanos, detentores de poder, estabelecidos por meio de uma ordem jurídica formada por um conjunto de ideias e instituições ${ }^{8}$.

$\mathrm{Na}$ esfera das ideias o Estado enquanto sociedade politicamente organizada deveria se constituir na sede exclusiva para a realização social e emancipação das subjetividades humanas, no referente de buscar a construção do bem comum e assegurar a liberdade (que seria natural do ser humano). Na esfera das instituições, o Estado se transformou em uma arena (como ordem) política-jurídica (fragmentada, na qual os interesses do poder atuam divididos) que tem por objetivo assegurar as liberdades individuais fundamentais.

Juridicamente Habermas ${ }^{9}$ define na obra A inclusão do outro, o Estado sob três pontos de vista: um objetivo, referindo-o como um poder estatal soberano $^{10}$, tanto interno como externamente; outro quanto a dimensão de

\footnotetext{
${ }^{6}$ DIAS, Maria da Graça dos Santos. Direito e Pós-modernidade. In: DIAS, Maria da Graça dos Santos; MELLO, Osvaldo Ferreira de; SILVA, Moacyr Motta da. Política Jurídica e Pós-modernidade. Florianópolis: Conceito Editorial, 2009.

${ }^{7}$ DIAS, Maria da Graça dos Santos. Direito e Pós-modernidade. In: DIAS, Maria da Graça dos Santos; MELLO, Osvaldo Ferreira de; SILVA, Moacyr Motta da. Política Jurídica e Pós-modernidade. Florianópolis: Conceito Editorial, 2009.

${ }^{8}$ OST, Franções. Mondialisation, Globalisation, Universalisation: s'arracher, encorre et toujours, à l'etat de nature. In: MORAND, Charles-Albert (org). Bruxelles: Bruylant, 2001.

${ }^{9}$ HABERMAS, Jürgen. A Inclusão do Outro: estudos de teoria política. Tradução de Goerge Sperber e Paulo Astor Soethe. São Paulo: Loyola, 2002.

${ }_{10}$ Para Jean Bodin, o poder soberano não está sujeito aos comandos de ninguém, nem mesmo aos comandos prévios do próprio soberano, sendo livre de qualquer carga ou condição, salvo as impostas pelas leis divinas e naturais. BONDIN, Jean. Os Seis Livros da República. Tradução, Introdução e Notas José Carlos Orsi Morel. Revisão Técnica da Tradução José Ignacio Coelho Mendes Neto. São Paulo: ÍCONE, 2011.
} 
espaço que se refere a uma área claramente delimitada, o chamado território ${ }^{11}$ do Estado; e por último, um ponto de vista social, que se refere ao conjunto dos seus integrantes, o povo ${ }^{12}$.

Em síntese, o Estado moderno pode ser caracterizado como uma organização formal das estruturas de poder, territorializado, que possui unidade interna, soberania, tripartição dos poderes, monopólio legítimo da força, que se assegura por meio do sistema jurídico unificado, centralizado (lei) e convertido como meio de comunicação (linguagem coercitiva) do Estado com a Sociedade Civil, com o fim de assegurar a liberdade e a segurança dos indivíduos, garantindo a paz pública.

\subsection{Estado Moderno e a Soberania}

A Soberania tem sido concebida de duas formas: como sinônimo de "independência" ou como expressão de "poder jurídico mais alto". Na prática, a Soberania é a oposição entre o poder supremo do Estado a outros poderes, desde que praticada nos limites do seu território.

Por sua vez o poder é um fenômeno social bilateral que decorre da união de duas ou mais vontades, prevalecendo uma sobre a outra. Sempre se perguntou qual a fonte do Poder Soberano. Na Antiguidade não havia dúvida que esse Poder advinha de Deus. No período medievo, onde se pregava-se a soberania absoluta do Rei. Jean Bodin ${ }^{13}$ ensinou que a soberania do rei era originária, ilimitada, absoluta, perpétua e irresponsável em face a qualquer outro poder temporal ou espiritual. Sob esse pressuposto, as monarquias absolutistas consolidaram-se na doutrina de Maquiavel ${ }^{14}$.

Com a evolução da história, conheceu-se as correntes que defendem o poder advindo da democracia, ou seja, a Soberania que provém da vontade do povo (teoria da soberania popular), da nação propriamente dita (teoria da soberania nacional), ou ainda, do próprio Estado (soberania do Estado).

A Soberania Popular que advém da vontade do povo já era defendida por São Tomás de Aquino e contrariava o Poder Absoluto. O poder civil correspondia com a vontade de Deus, mas promanava da vontade popular. O povo possuía o direito de resistência e de limitação aos poderes do Rei, fundamentos do ideal democrático. Assim, o Poder, seja exercido pelo Rei ou

\footnotetext{
11 "Definiu Pergolesi o território como a 'parte do globo terrestre na qual se acha efetivamente fixado o elemento populacional, com exclusão da soberania de qualquer outro Estado". BONAVIDES, Paulo. Ciência Política. 12. ed., São Paulo: Malheiros, 2006. p. 94.

12 "Deve-se compreender como povo o conjunto dos indivíduos que, através de um momento jurídico, se unem para constituir o Estado, estabelecendo com este um vínculo de caráter permanente, participando da formação da vontade do Estado e do exercício do poder soberano". DALLARI, Dalmo de Abreu. Elementos da Teoria Geral do Estado. 25. ed., São Paulo: Saraiva, 2005. p. 99-100.

${ }^{13}$ BONDIN, Jean. Os Seis Livros da República. Tradução, Introdução e Notas José Carlos Orsi Morel. Revisão Técnica da Tradução José Ignacio Coelho Mendes Neto. São Paulo: íCONE, 2011.

${ }^{14}$ MACCHIAVELLI, Niccolò. O Príncipe: comentários de Napoleão Bonaparte e Cristina da Suécia. Tradução e revisão de Ana Paula Pessoa. São Paulo: Jardim dos Livros, 2007.
} 
por outra autoridade, seria sempre constituído, e ressaltava a existência de um Poder maior exercido pelo povo que se denominou Soberania ou Poder Constituinte.

A Teoria da Soberania Nacional ganhou corpo com a Revolução Francesa: "a Coroa não pertence ao Rei; o Rei é que pertence à Coroa. O Rei é depositário, não é proprietário". Essa teoria pertencente a escola clássica francesa, mostra-se extremamente nacionalista e radical, excluindo, por exemplo, os não nacionais de seu contexto. Finalmente, a Soberania do Estado parte do princípio que, a soberania é a capacidade de autodeterminação do Estado por direito próprio e exclusivo. Traduz o pensamento filosófico de Ihering ${ }^{15}$, segundo o qual a Soberania é uma qualidade do poder do Estado perfeito e anterior ao direito.

O direito é feito pelo Estado e para o Estado. A Soberania é um poder jurídico que tem sua fonte e sua justificativa na própria vontade do Estado.

Nessa linha segue Kelsen para quem a soberania é de natureza estritamente jurídica, é um direito do Estado de caráter absoluto. "Toda forma de coação do Estado é legítima, porque tende a realizar o direito como expressão da vontade soberana do Estado" ${ }^{16}$.

É necessário admitir que a Soberania origina-se na nação. Contudo, só adquire expressão concreta e objetiva quando se institucionaliza no órgão estatal, recebendo através deste o seu ordenamento jurídico-formal dinâmico.

Em síntese, a Soberania é originariamente da Nação (quanto a ser fonte de poder), mas juridicamente, do Estado (quanto ao seu exercício). Portanto, se for certo que Nação e Estado são realidades distintas, uma sociológica outra jurídica, é certo também que ambas compõem uma só personalidade no campo do Direito Público Internacional. E nesse campo não se projeta a soberania como vontade do povo, mas como vontade do Estado, que é Nação politicamente organizada.

\subsubsection{Soberania: qualidade do poder soberano}

Machado Paupério ${ }^{17}$ na clássica obra 0 conceito polêmico de soberania conclui que a Soberania não é propriamente um poder, mas sim, a qualidade desse poder. É um atributo de que reveste o poder de auto-organização nacional, de autodeterminação institucionalizado no órgão estatal.

O chamado poder soberano exerce uma função de coordenação e de coesão entre os integrantes de uma sociedade. Sem o poder não existiria ordem, organização da sociedade, e essa rumaria ao caos, pois o poder é natural em qualquer tipo de sociedade e necessário para o ato de governar.

\footnotetext{
${ }^{15}$ IHERING, Rudolf Von. A Luta pelo Direito. São Paulo: Rideel, 2005.

${ }^{16}$ KELSEN, Hans. A Democracia. Tradução de Ivone Castilho Benedetti, Jefferson Luiz Camargo, Marcelo Brandão Cipolla e Vera Barkow. São Paulo: Martins Fontes, 2000.

${ }^{17}$ PAUPÉRIO, Machado. O Conceito Polêmico de Soberania. 2. ed., Rio de Janeiro: Freitas Bastos, 1958.
} 
O poder soberano exerce sua força em âmbitos distintos, podendo assim ser denominado de Poder Social, Jurídico ou Político, que para Celso Ribeiro Bastos $^{18}$ podem assim ser considerados:

1) Poder Social consiste na faculdade de alguém impor a sua vontade a outrem. O poder social não deve ser confundido com a utilização da força física, embora possa haver coercitividade. Ele pode se apresentar através da mera persuasão, que pressupõe a prática argumentativa. Podem-se citar como exemplos: os poderes sociais, os económicos, religiosos e sindicais.

2) O Poder Político é aquele exercido no Estado e pelo Estado. Não pode e nem deve ser confundido com a Soberania, que é quem lhe empresta o poder. Poder Político é o comando, é a própria administração estatal. Como Poder Político a Soberania é considerada a "força do direito", pode ser ilimitada na medida que advém de um Poder Constituinte Originário, incondicional e preocupado em assegurar sua eficácia.

3) A Soberania como Poder Jurídico é o "direito da força", limitada por tratar-se de um Poder Constituído (secundário, não originário), nascido do direito e exercido exclusivamente para a consecução dos fins jurídicos do Estado.

Só conseguimos entender a soberania como a conhecemos hoje, após passar por seu processo evolutivo, vez que era desconhecida na antiguidade e no tempo medieval. Aristóteles ${ }^{19}$ aludia ao termo "autarquia" e em Roma se falou da suprema potestas como última sede de poder.

A ideia de soberania é um conceito que emerge e se consagra já nos anos de 1500. No entanto, somente a partir do século XVI os reis da Europa adquiriram suficiente ascendência nos seus territórios a ponto de serem chamados de Soberanos.

Com Jean Jacques Rousseau ${ }^{20}$ a soberania sai das mãos do monarca e sua titularidade se consubstancia no povo. No séc. XIX aparece como emanação do poder político. Posteriormente será o próprio Estado como personalidade jurídica que deterá a titularidade da mesma.

A soberania como poder ilimitado já não é mais útil nos dias atuais. O Estado e o exercício do poder encontram-se limitados e condicionado, tanto interno como externamente, por circunstâncias demográficas, econômicas, tecnológicas (que não podem ser alteradas por manifestações unilaterais), e pelos novos ambientes assimétricos possibilitados pelas tecnologias que os colocam diante de uma nova realidade de comunicação.

\footnotetext{
${ }^{18}$ BASTOS, Celso Ribeiro. Teoria do Estado e Ciência Política. 5. ed., São Paulo: Celso Bastos, 2002.

${ }^{19}$ ARISTÓTELES. Política. Tradução de Mário da Gama Kury. Brasília: UnB, 1985.

${ }^{20}$ ROUSSEAU, Jean-Jacques. O Contrato Social. Tradução de Antônio de P. Machado. Rio de Janeiro: Ediouro, 1995.
} 


\subsubsection{A Relativização da Soberania}

Quanto à questão da soberania Gustavo Zagrebelsky ${ }^{21}$ no livro El derecho dúctil: ley, derechos, justicia chama atenção para as mudanças ocorridas no mundo nas últimas décadas, e que estão transformando o Estado Constitucional e a sua soberania.

Sem dúvida que o conceito de Soberania elaborado por Bodin e Hobbes - Teorias do Estado - ratificado através do Tratado da Paz de Westfália em 1648, esteve historicamente vinculado à nacionalização jurídica do Poder.

A soberania, entendida originalmente, como situação eficiente, como uma força material empenhada em construir e garantir a supremacia e a unidade da esfera política, através de um sistema interestatal e, um modelo de ordem internacional caracterizado por: a) um mundo composto e dividido por Estados soberanos que não reconhecem nenhuma autoridade superior ao Estado; b) os processos de produção do direito, resolução de demandas (disputas) e execução da lei, estão basicamente nas mãos dos Estados individuais; c) o direito internacional se orienta através do estabelecimento de regras mínimas de coexistência. A criação de relações douradoras entre os Estados e os povos, somente seria promovida quando atendesse objetivos políticos nacionais; d) a responsabilidade por ações ilegais transfronteirizas seria um assunto privado que concerne aos afetados; e) todos os Estados são considerados iguais perante a lei: as disposições legais não levam em conta as assimetrias do poder; f) as diferenças entre os Estados são em última instância resolvidas pela violência. Predominância do princípio do poder efetivo. Praticamente não existem freios legais para conter o recurso da força, vez que as normas internacionais garantem uma mínima proteção; g) a minimização das restrições à liberdade do Estado é a propriedade privada.

O marco Westfaliano de assuntos nacionais e internacionais demarcou de forma persistente e paradoxal, um sistema internacional de Estados interconectados, em constante desenvolvimento e expansão, fortalecendo o direito de cada Estado a agir de forma independente e autônoma, portanto, soberana.

A soberania possuía duas perspectivas, uma interna e outra externa. Pela primeira, a soberania indicava a incomensurabilidade do Estado frente a qualquer outro sujeito e, portanto, a impossibilidade de entrar em relações jurídicas com eles, frente ao Estado soberano não poderia existir mais que relações de sujeição. Pela segunda, os Estados se representavam como fortalezas fechadas, protegidas pelo princípio da não ingerência dos Estados, somente afetado pelas Guerras (típicas lutas pela garantia da soberania) ${ }^{22}$.

No entanto, desde o final do século passado foças vigorosas e corrosivas,

\footnotetext{
${ }^{21}$ ZAGREBELSKY, Gustavo. El Derecho Dúctil: ley, derechos, justicia. 6. ed., Traducción de Marina Gascón. Madri: Trotta, 2005.

${ }^{22}$ ZAGREBELSKY, Gustavo. El Derecho Dúctil: ley, derechos, justicia. 6. ed., Traducción de Marina Gascón. Madri: Trotta, 2005.
} 
tanto no âmbito interna como externa, tais como: o pluralismo político e social interno (que se opõe a ideia de soberania e de sujeição); a formação de centros do poder alternativos e concorrentes com o Estado (que operam em um campo político, econômico, cultural e religioso, com dimensões totalmente independentes da territorialidade estatal); a progressiva institucionalização de dimensões supranacionais promovida pelos próprios Estados (que visam à integração dos poderes, e a atribuição cada vez maior de direitos aos indivíduos que podem se valer de jurisdições internacionais frente aos Estados); o fenômeno da transnacionalização dos riscos ambientais, econômicos e sociais, e a globalização da economia, da cultura, das pessoas, bens e serviços, dentre outras (que se colocam como fatores molestadores (quebra) da soberania), abrem espaço para um grande debate sobre a crise do Estado Constitucional Moderno.

\section{ESTADO CONSTITUCIONAL MODERNO EM CRISE}

Para que se abra o debate sobre a crise (risco) do Estado Constitucional moderno ${ }^{23}$ e, apresentar possíveis respostas e/ou novos papéis dos Estados, diante da complexidade das demandas (desafios) transnacionais, tais como o aumento da problemática ambiental, social, econômica e culturais vivenciadas pelos Estados nacionais nas últimas décadas, parece ser imprescindível considerar que, a liberação do mercado mundial prosperou muito com o liberalismo transnacional, como evidenciou Jürgen Habermas ${ }^{24}$ e que mudou o sistema de produção de riquezas, antes territorializado no âmbito estatal, agora globalizado (transnacionalizado).

O mercado estabeleceu suas próprias regras, "[...] nenhuma delas é uma regra de fortalecimento do espaço público e consequentemente do Estado. Natural resultado é a fragilidade do discurso jurídico estatal" ${ }^{25}$. Na verdade, as profundas mudanças promovidas pela globalização do plural ${ }^{26}$ (economia (capitalismo), ciência, cultura, técnica, sistemas de saúde, previdências sociais, meios transportes, ações militares, mídia e do turismo) considerados por Gunther Teubner $^{27}$ no artigo A Bukowina global sobre a emergência de um

\footnotetext{
${ }^{23}$ O Estado Constitucional Moderno "[...] é gênero do qual Estado Liberal, Estado Social, Estado de Bem-Estar, Estado contemporâneo e todas as outras denominações dadas às variações do seu âmbito de atuação são espécies. Ou seja, há uma só matriz político-jurídica com vários modelos que foram surgindo a partir de decisões - ou necessidades - ideológicas" CRUZ, Paulo Márcio. Da Soberania a Transnacionalidade: democracia, direito e estado no século XXI. Seleção e organização dos capítulos Emanuela Cristina Andrade Lacerda. Itajaí: UNIVALI, 2011. p. 34.

${ }^{24}$ HABERMAS, Jürgen. A Constelação Pós-nacional: ensaios políticos. Tradução de Márcio Seligmann Silva. São Paulo: Littera Mundi, 2001.

${ }^{25}$ BELLO FILHO, Ney de Barros. Pressupostos Sociológicos e Dogmáticos da Fundamentalidade do Direito ao Ambiente Sadio e Ecologicamente Equilibrado. Tese de Doutorado. Universidade Federal de Santa Catarina. 2006. p. 159.

${ }^{26}$ HÖFFE, Otfried. A Democracia no Mundo de Hoje. Tradução de Tito Lívio Romão, revisão da tradução de Luz Moreira. São Paulo: Martins Fontes, 2005.

27 TEUBNER, Gunther. A Bukowina Global sobre a Emergência de um Pluralismo Jurídico Transnacional. Impulso. Piracicaba, 14(33): 9-31, 2003, p. 13. Disponível em: <http://www.unimep.br/ phpg/editora/revistaspdf/imp33art01.pdf>. Acesso em: 02 jan. 2014.
} 
pluralismo jurídico transnacional, como dos sistemas mundiais autônomos, não foram acompanhadas pela política estatal, que atingiu a forma de relações internacionais.

O Estado "proto-globalizado", possibilitou tão-somente relações intersistêmicas entre unidades nacionais com elementos internacionais relativamente fracos. O que nos leva a perceber que um dos principais fatores de crise do Estado Constitucional moderno está localizado exatamente na falta de regulamentação e atuação de pautas que não estão albergadas pela territorialidade de jurisdição estatal.

Friedrich Müller $^{28}$ um dos principais pesquisadores contemporâneos sobre a temática, na obra Que grau de exclusão social ainda pode ser tolerado por um sistema democrático é enfático ao afirmar que os Estados Constitucionais modernos e os seus sistemas democráticos parecem não conseguir dar respostas consistentes à sociedade diante do grau de exclusão social, dos novos ambientes assimétricos da comunicação e do poder, da potência destrutiva das armas nucleares, das agressões contra o meio ambiente, do aumento das desigualdades sociais, da explosão dos conflitos étnicos e da hipertrofia do mercado, que procura dissolver a hegemonia da soberania estatal e do seu direito, buscando alternativas de imposição de regras de conduta que não são jurídicas e estatais ${ }^{29}$.

Para o seu fortalecimento o Estado passou a assumir mais tarefas, para alcançar mais poder ${ }^{30}$. No entanto, o que está ocorrendo parece ser um movimento oposto, ou seja, a destituição cada vez maior do Estado. Apesar do esforço incessante dos Estados de não se submeterem a ulteriores poderes, sobretudo, poderes públicos estrangeiros, apoiando-se no conceito clássico de soberania, o que se percebe nos últimos anos é um crescimento das interdependências econômicas e um aumento significativo do acoplamento estrutural dos processos sociais, mormente, após a queda do contraponto socialista e a hegemonização ocidental do capitalismo liberal.

O hipercapitalismo ou cultura global do mercado se tornou paradigma dominante na modernidade ${ }^{31}$. Desde os anos de 1980, o capitalismo entrou em um novo ciclo de funcionamento, marcado pelo desmantelamento dos antigos controles de regulamentação que limitavam o mercado concorrencial ${ }^{32}$. O capitalismo enquanto sinônimo do liberalismo se transformou em "liberado",

\footnotetext{
${ }^{28}$ MÜLLER, Friedrich. Que Grau de Exclusão Social ainda pode ser Tolerado por um Sistema Democrático?. Porto Alegre: Unidade Editorial, 2000.

${ }^{29}$ BELLO FILHO, Ney de Barro. Pressupostos Sociológicos e Dogmáticos da Fundamentalidade do Direito ao Ambiente Sadio e Ecologicamente Equilibrado. Tese de Doutorado. Universidade Federal de Santa Catarina. 2006.

${ }^{30}$ HÖFFE, Otfried. A Democracia no Mundo de Hoje. Tradução de Tito Lívio Romão, revisão da tradução de Luz Moreira. São Paulo: Martins Fontes, 2005.

${ }^{31}$ LIPOVESTSKY, Gilles; SERROY, Jean. A Cultura Mundo: resposta a uma sociedade desorientada. Tradução de Maria Lúcia Machado. São Paulo: Companhia das Letras, 2011.

${ }^{32}$ GIDDENS, Anthony. As Consequências da Modernidade. Tradução de Raul Filker. São Paulo: Unesp, 1991.
} 
condicionando praticamente todo o mundo a internalizar a cultura global do mercado.

A livre-troca propagou-se praticamente no mundo todo. A nova era global estabeleceu também uma nova época de desequilíbrios de imprevisibilidade e de caos crescentes, instalando-se uma insegurança criada pela desregulamentação global das atividades transnacionais financeiras, criminosas e de riscos. O mercado está conseguindo esvaziar o espaço político e jurídico (espaços públicos) do Estado. Como afirmava Milton Santos em sua obra Por uma outra globalização, a "[...] política agora é feita no mercado. Só que esse mercado global não existe como ator, mas como ideologia, como símbolo"33.

O mercado é resultado do projeto moderno liberal que, cientificou o mundo da vida, com o objetivo de tornar a relação do homem com o meio em recurso e não em valor. A todo recurso, pode-se atribuir um preço, o que não ocorre com o valor.

Dessa forma, as bases axiológicas modernas possibilitaram que o capitalismo pudesse se transformar em hipercapitalismo, em um sistema (poder) econômico de mercado sem regulação, que pela primeira vez se desenvolve sem um verdadeiro concorrente. Nunca o economismo, a concorrência, o espírito de eficácia se impuseram de maneira tão ampla. "O fato está aí: o espírito de tempo converteu-se no espírito do capitalismo, funcionando como uma cultura sem fronteiras, uma cultura-mundo"34.

Neste mundo globalizado, a competividade, o consumo, a confusão dos espíritos, constituem baluartes do presente estado das coisas. "A competitividade comanda nossas formas de ação. O consumo comanda nossas formas de inação. E a confusão dos espíritos impede o nosso entendimento do mundo, do país, do lugar, da sociedade e de cada um de nós mesmos"35.

Jürgen Habermas afirmava em 1997 que embora o capitalismo tenha se desenvolvido desde o início em dimensões mundiais ele se consolidou inicialmente no Estado Nacional, que por sua vez se concretizou através da dinâmica econômica. Mas, já faz tempo que esses dois processos deixaram de se fortalecer reciprocamente. "É certo que a limitação territorial do capital jamais correspondeu à sua mobilidade estrutural. Ela se deveu às condições históricas da sociedade burguesa $[. . .]^{\prime 36}$. A mobilidade passa a ser entendida como desnacionalização da produção econômica.

Nesse sentido, é preciso entender que o capitalismo desnacionalizado, "solto", "desteorizado" e "desterritorializado", portanto, "despolitizado", formou uma tecnoestrutura em rede global que mais nada tem haver com o livre

\footnotetext{
${ }^{33}$ SANTOS, Milton. Por uma outra Globalização. São Paulo: Record, 2001.

${ }^{34}$ LIPOVESTSKY, Gilles; SERROY, Jean. A Cultura Mundo: resposta a uma sociedade desorientada. Tradução de Maria Lúcia Machado. São Paulo: Companhia das Letras, 2011.

${ }^{35}$ SANTOS, Milton. Por uma outra Globalização. São Paulo: Record, 2001.

36 HABERMAS, Jürgen. A Constelação Pós-nacional: ensaios políticos. Tradução de Márcio Seligmann Silva. São Paulo: Littera Mundi, 2001.
} 
mercado, sobretudo, porque o capitalismo contemporâneo se estriba num sistema assentado em cinco monopólios: das finanças; tecnológico; energético; das comunicações e militar.

Desde esse ponto de vida, evidencia-se a importância e a necessidade da politização das demandas econômicas (primordialmente do capitalismo) que também deverá ser globalizada, para que as organizações capitalistas não levem a cabo o processo de tomada de poder global. Essa nova necessidade implica instituir novos tipos de poderes (governança) democráticos, que deverão introduzir imensos desafios na prática da política mundial (transnacional).

Gilberto Dupas na obra Atores e poderes na nova ordem global: assimetrias, instabilidades e imperativos de legitimação enfatiza: "No pósglobalização os Estados deixam de constituir-se nos atores mais relevantes da ação coletiva e não regulam os sistemas de regras da ação política que definem e modificam os cenários das ações coletivas",37, afirma ainda, com a "[...] liberação das fronteiras surgem jogos suplementares, novos papéis e regras desconhecidas, bem como novas contradições e conflitos" ${ }^{\prime 38}$

Nessa linha, vê-se despontar à necessidade de ação que não se atém única e exclusivamente as fronteiras Estatais ${ }^{39}$, no entanto, será necessário observar os novos ambientes assimétricos das sociedades complexas pós-modernas.

\subsection{A Decadência (crise) da Autoridade Estatal e a Crescente Interconexão Mundial}

Em sua obra La democracia y el orden global: Del Estado moderno al gobierno cosmopolita, David Held ${ }^{40}$ professor de política e sociologia da Open University apresenta um importante diagnóstico do sistema internacional de Estados, e as transformações da globalização, apontando para a exigência da colaboração dos Estados-nações de forma mais intensa, no sentido de possibilitar o estabelecimento da democracia como uma estrutura comum, transnacional. Ao expor seus argumentos o teórico político britânico sugere que os significados das instituições políticas atuais devem ser explorados sob o contexto de uma sociedade complexa, considerando que Estado moderno está cada vez mais atropelado por redes de interconexão mundial, permeadas por forças supranacionais, intergovernamentais e transnacionais. Cada vez menos o Estado é capaz de determinar seu próprio destino.

De maneira esquemática, Held apresenta as razões que podem explicar a crescente interconexão mundial, razões que conduzem a decadência (crise)

\footnotetext{
${ }^{37}$ DUPAS, Gilberto. Atores e Poderes na Nova Ordem Global: Assimetrias, instabilidades e imperativos da legitimação. São Paulo: UNESP, 2005. p. 36.

${ }^{38}$ DUPAS, Gilberto. Atores e Poderes na Nova Ordem Global: Assimetrias, instabilidades e imperativos da legitimação. São Paulo: UNESP, 2005. p. 36.

${ }^{39}$ HÖFFE, Otfried. A Democracia no Mundo de Hoje. Tradução de Tito Lívio Romão, revisão da tradução de Luz Moreira. São Paulo: Martins Fontes, 2005.

${ }^{40}$ HELD, David. La Democracia y el Orden Global: Del Estado moderno al gobierno cosmopolita. Traducción de Sebastián Mazzuca. Barcelona: Paidós, 2002.
} 
da autoridade estatal, exigindo que os Estados nacionais e as organizações colaborem de forma mais intensa, veja-se:

1) $\mathrm{Na}$ politica internacional a concepção tradicional de relação entre o Estado e a sociedade, na qual o primeiro é postulado como uma unidade fundamental da ordem mundial, supõe a homogeneidade do Estado e outros tipos de atores chaves, ou seja, que se trata de entidades com propósitos singulares. Porém o crescimento das organizações, coletividades internacionais e transnacionais, como a ONU e suas organizações até os movimentos sociais e grupos de pressão especiais, alterou a forma e a dinâmica tanto do Estado como da sociedade. A intensificação dos processos de interconexão regional e global, a proliferação de acordos internacionais e as novas formas de cooperação intergovernamental, que visavam regular o crescimento sem precedentes desses fenômenos, especialmente durante o período posterior a Segunda Guerra Mundial, erosionaram a distinção entre os assuntos internos e externos, entre política internacional e doméstica. O Estado se converteu em uma arena fragmentada de elaboração politica, permeado por grupos internacionais (governamentais e não governamentais), agências e forças domésticas. A penetração geral de sociedade civil por atores transnacionais alterou a sua forma e dinâmica.

2) A interconexão global e a quantidade de instrumentos políticos a disposição dos governos individuais e a efetividade desses instrumentos mostra uma clara tendência a declinar. Esta tendência responde, em primeiro lugar, a perda de um amplo espectro de controles - formais e informais sobre as fronteiras, que anteriormente serviam para restringir a circulação de bens, serviços, fatores de produção, tecnologia e intercâmbio de ideias e culturas. O resultado de tudo isso é a alteração dos custos e benefícios para programar diferentes opções políticas e a diminuição da eficácia daqueles instrumentos que permitem o Estado de controlar as atividades dentre e através das fronteiras.

3) Os Estados podem experimentar uma nova redução das opções devido a expansão das forças e interações transnacionais que reduzem e restringem a influência dos governos particulares sobre as atividades de seus cidadãos. O impacto do fluxo de capital privado através das fronteiras pode colocar em perigo as medidas anti-inflacionárias, as taxas de cambio, a política impositiva e outras disposições governamentais.

4) No contexto de uma ordem global altamente interconectada, muitos dos domínios tradicionais das atividades e responsabilidades estatais (defesa, gestão econômica, comunicações, sistemas administrativos e legais) não podem ser regidos sem recorrer às formas internacionais de cooperação. Posto que as demandas que devem atender aumentaram consideravelmente nos anos pós-guerra. Nesse sentindo, o Estado passou a enfrentar um conjunto de problemas políticos, que não podem ser resolvidos adequadamente sem a colaboração de outros Estados e atores não estatais (transnacionais). Os Estados individuais não são as únicas unidades políticas para resolver 
problemas políticos chaves, tão pouco, para ampliar o espectro de funções públicas;

5) Os Estados também aumentaram o nível de integração política com outros Estados (por exemplo, através de redes regionais como a União Europeia e a Organização de Estados Americanos), e/ou impulsionaram negociações, acordos e instituições multilaterais para poder controlar os efeitos desestabilizadores que acompanham a interconexão (por exemplo, o Fundo Monetário Internacional e o Banco Mundial, que, junto com outras agências internacionais, geraram um ambiente organizativo especial para a gestão econômica e a consulta intergovernamental depois de Segunda Guerra Mundial) e,

6) O resultado foi um importante crescimento de instituições, organizações e regimes, que sustentam as bases para organizar os assuntos globais, isto é, um governo mundial. Não pode-se confundir esse desenvolvimento, com a emergência de um governo mundial integrado. Existe uma diferença entre uma sociedade internacional, que mantem a possibilidade de ordem e cooperação política e um Estado supranacional que detenha o monopólio da poder coercitivo e legislativo.

A nova política global - implica, entre outras coisas, em processos de tomada de decisão multi-burocráticos, entre e dentro das burocracias governamentais e internacionais, políticas induzidas por agências e forças internacionais e novas formas de integração multinacional entre os Estados. Criou-se um marco dentro e através do qual se redefinem os direitos e obrigações, os poderes e as capacidades dos Estados.

Estes argumentos sugerem que o Estado moderno está cada vez mais atropelado por redes de interconexão mundial, por novos ambientes assimétricos de participação e conexão, e que a globalização pode ser retratada como uma força homogeneizadora que elimina a diferença política e as capacidades dos Estados nações para atuar de forma independente.

Se for verdade que o Estado nação está em decadência, não é verdadeiro que seja como um processo igual, antes é um processo desigual, sobretudo, porque alguns Estados nem se quer ainda conseguiram se consolidar como Estado nação, como Estado Constitucional de Direitos ${ }^{41}$.

Em resumo, a proliferação de pautas, agentes, organizações e instituições regionais, internacionais e transnacionais (governamentais e não governamentais), o crescimento da interconexão mundial por meio de algumas dimensões chaves, como a economia, a política, a tecnologia, a comunicação e o direito; a crescente permeabilidade das fronteiras, a diminuição da capacidade dos Estados de gerar instrumentos políticos idôneos, para controlar o fluxo de bens, serviços, ideias e produtos culturais, etc., a crescente necessidade dos Estados

\footnotetext{
${ }^{41}$ HELD, David. La Democracia y el Orden Global: Del Estado moderno al gobierno cosmopolita. Traducción de Sebastián Mazzuca. Barcelona: Paidós, 2002. p. 120.
} 
de cooperar entre si, para controlar as consequências políticas da globalização, o aumento das agências e instituições internacionais (como mecanismos para tentar manter o equilíbrio do poder), expansão dos regimes democráticos, o desenvolvimento de organizações internacionais e da diplomacia multilateral, ampliação do alcance do direito internacional e a cooperação com atores e processos não estatais e transnacionais, criaram novos desafios para o poder do Estado, para o sistema interestatal e para a teoria e prática democrática.

Cabe então, aos pensadores contemporâneos teorizar possíveis resoluções institucionais e/ou não institucionais, que possibilitem que Estados, indivíduos e organizações, seja da sociedade civil ou empresarial, colaborem entre si de forma mais intensa, democrática e transnacional, e, que possam diminuir as assimetrias do poder, econômicas, culturais e sociais existentes entre os Estados.

\section{O FENÔMENO DAS GLOBALIZAÇÕES}

Com o intento de estabelecer um acordo semântico sobre o conceito operacional da categoria globalização, de modo a lançar luz a respeito da temática, sem desfazer-se das discussões conceituais e teóricas, por si só, passiveis de muita investigação, este texto filia-se ao pensamento de Ulrich Beck apresentado no livro $O$ que é globalização para quem a globalização representa, "[...] os processos, em cujo andamento, os Estados nacionais veem a sua soberania, sua identidade, suas redes de comunicação, suas chances de poder e suas orientações, sofrer a interferência cruzada de atores transnacionais" ${ }^{\prime 2}$.

O conceito de globalização, como um processo ("dialético") que produz as conexões, os espaços transnacionais e sociais, que revaloriza culturas locais e põem em cena novas culturas - um pouco disso, um pouco daquilo, assim vão surgindo às novidades no mundo ${ }^{43}$ - resignifica a experiência cotidiana da ação sem fronteiras, nas dimensões da economia, informação, ecologia, técnica, conflitos transculturais e da sociedade.

Nas palavras de Jürgen Habermas ${ }^{44}$ a globalização se apresenta como um processo, não de um estado final, mas que se caracteriza com uma quantidade cada vez maior (intensificação) das relações de troca, comunicação e de trânsito para além das fronteiras nacionais. Trata-se de "[...] um processo complexo que atravessa as mais diversas áreas da vida social, da globalização dos sistemas produtivos e financeiros, à revolução nas tecnologias e práticas de informação e de comunicação, e da erosão do Estado nacional [...]" ${ }^{\prime 4}$.

\footnotetext{
${ }^{42}$ BECK, Ulrich. O que é globalização? equívocos do globalismo: resposta à globalização. Tradução de André Carone. São Paulo: Paz e Terra, 1999. p. 30-33.

${ }^{43}$ BECK, Ulrich. O que é globalização? equívocos do globalismo: resposta à globalização. Tradução de André Carone. São Paulo: Paz e Terra, 1999. p. 30-33.

${ }^{44}$ HABERMAS, Jürgen. A Constelação Pós-nacional: ensaios políticos. Tradução de Márcio Seligmann Silva. São Paulo: Littera Mundi, 2001.

${ }^{45}$ HABERMAS, Jürgen. A Inclusão do Outro: estudos de teoria política. Tradução de Goerge Sperber e Paulo Astor Soethe. São Paulo: Loyola, 2002. p. 11.
} 
Importante ressaltar ainda, que globalização significa também a "[...] negação do Estado Mundial. Mais precisamente: sociedade mundial sem Estado Mundial e sem governo mundial. Está se disseminando um capitalismo global desorganizado, pois não há poder hegemônico ou regime internacional econômico ou político" ${ }^{46}$ que consiga regular por hora em nível transnacional o capitalismo.

Ao tratar do tema e visando estabelecer as bases epistemológicas sobre o conceito de Globalização a professora Joana Stelzer, no texto O fenômeno da transnacionalização da dimensão jurídica, definiu "[...] a globalização como um processo dialético que produz as conexões e os espaços transnacionais e sociais, a desnacionalização, a experiência cotidiana da ação sem fronteira"47. Esta definição afeta as bases territoriais dos Estados e suas fronteiras. A territorialidade deixa de ser importante nesse novo mundo, fortemente estabelecido por interações não governamentais.

Neste viés, a Globalização transformou o modelo Westfaliano da sociedade de Estados e sociedade internacional, em um modelo de ordem transnacional ${ }^{48}$. A globalização tornou-se um processo de consequências associadas, que ocorre de maneira pluridimensional, e que não se expressa somente com a globalização econômica. A globalização é também multiplicidade política, social e cultural: nova necessidade de desenvolver formas de vida em dimensões transnacionais $^{49}$.

Portanto, ao se abrir espaço para a pluridimensionalidade e a multiplicidade da vida, também será necessário no campo político reconhecer uma pluralização de novos atores, ou seja, o Estado não é mais o único ator que comercializa e interage em âmbito internacional ou que mantém relações diplomáticas, estão aparecendo novos atores transnacionais, que vão desde a Organização Mundial do Comércio - OMC até a Anistia Internacional, diversos grupos e igrejas, que estão elevando a voz e buscando consolidar a sua força no jogo de poder da sociedade transnacional.

\subsection{Globalizações: econômica, social e política}

A análise do fenômeno da globalização ficaria incompleta, se reconhecêssemos somente os fatores que possibilitariam a emergência hegemônica da economia capitalista, da técnica e as interferências na soberania dos Estados-nações ${ }^{50}$. Assim, parece ser imperioso observar a emergência de certo número de sinais indicativos de outros processos globalizantes que

\footnotetext{
${ }^{46}$ BECK, Ulrich. O que é globalização? equívocos do globalismo: resposta à globalização. Tradução de André Carone. São Paulo: Paz e Terra, 1999. p. 30-33.

${ }^{47}$ STELZER, Joana. O Fenômeno da Transnacionalização de Dimensão Jurídica. In: CRUZ, Paulo Márcio; STELZER, Joana. (orgs.). Direito de Transnacionalidade. Curitiba: Juruá, 2009. p. 20.

${ }^{48}$ OST, Franções. Mondialisation, Globalisation, Universalisation: s'arracher, encorre et toujours, à I'etat de nature. In: MORAND, Charles-Albert (org). Bruxelles: Bruylant, 2001.

${ }^{49}$ BECK, Ulrich. O que é globalização? equívocos do globalismo: resposta à globalização. Tradução de André Carone. São Paulo: Paz e Terra, 1999.

${ }^{50}$ SANTOS, Milton. Por uma outra Globalização. São Paulo: Record, 2001.
} 
também se levantam, autorizando-se a pensar que se vive uma verdadeira fase de transição para um novo-período que pode ser caraterizado como pós-moderno.

Jeremy Rifkin ${ }^{51}$ enfatiza que pela primeira vez na história da humanidade, a maioria da espécie humana faz parte de infraestruturas econômicas, sociais e políticas que se estendem por todo o globo. É verdade que um percentual significativo da população mundial segue excluída e desconectada do processo de globalização, no entanto, são (seguramente) afetadas pelos seus processos e aspectos exteriores.

A estrutura lógica do comércio e os intercâmbios se tornaram praticamente comuns a todos. Frutas, verduras, cereais, carne, produtos eletrônicos, carros, combustíveis, que se produzem a milhões de quilômetros são transportados todos os dias, e oferecidos nos supermercados do mundo inteiro (uma parcela significativa da população mundial segue sem acesso a alimentação). A mão de obra de trabalho transpassou as fronteiras nacionais (por vezes de forma legal, outras ilegais).

A economia (capitalista) parece ter se tornado global, acompanhada por instituições econômicas, de alcance global como o Banco Mundial, a Organização Mundial do Comércio (OMC), o Fundo Monetário Internacional (FMI), espaços políticos supranacionais como a União Europeia e as Nações Unidas (ONU), organizações intergovernamentais reguladoras, como Organização Mundial da Saúde (OMS) e a Organização Meteorológica Mundial (OMM), bem como, organizações mundiais de justiça como a Corte Penal Internacional e Corte Interamericana de Direitos Humanos.

Esta ampla rede de instituições econômicas, sociais, políticas, jurídicas e principalmente de comunicação (meios de comunicação ${ }^{52}$ ) estão criando a possibilidade de ambientes assimétricos sem precedentes na história da humanidade.

Parece evidente que o processo globalizador tem sido oportunista e destrutivo ${ }^{53}$. Por outro lado, a globalização produziu um impacto psicológico (oportunista certas vezes) tão importante quanto o econômico (teoricamente destrutivo). Para o autor em comento, muita atenção se tem dado as relações

\footnotetext{
${ }^{51}$ RIFKIN, Jeremy. La Civilización Empática. La Carrera hacia una Conciencia Global en un Mundo en Crisis. Tradução de Genis Sánchez Barverán e Vanessa Casanova. 1. ed., Mardri: Paidós, 2010. ${ }^{52}$ Em sua obra "A realidade dos Meios de Comunicação" Luhmann enfatiza que os meios de comunicação devem ser compreendidos, considerando todas as instituições da sociedade que se servem de meios técnicos de reprodução para a difusão da comunicação, considerando-se os livros, revistas, jornais produzidos de forma impressa, mas também processos de reprodução fotográfica ou eletrônica de qualquer tipo. Também consideram-se como meios de comunicação aquela realizada por rádios, a produção de massa, a comunicação em massa, bem como, as novas tecnologias de difusão de informações. LUHMANN, Niklas. A Realidade dos Meios de Comunicação. São Paulo: Paulus, 2005. p. 16-17.

${ }^{53}$ RIFKIN, Jeremy. La Civilización Empática. La Carrera hacia una Conciencia Global en un Mundo en Crisis. Tradução de Genis Sánchez Barverán e Vanessa Casanova. 1. ed., Mardri: Paidós, 2010.
} 
violentas provocadas pela globalização (xenofobia, populismo político e terrorismo), contudo, não se tem prestado atenção na crescente extensão empática que o processo globalizador de técnica tem proporcionado.

Milhões de pessoas estão em constante contato com outras pessoas, assim, o já ilimitado mundo do mercado global também tem sido acompanhado de um espaço social que é ainda mais ilimitado, sobretudo, pelas redes sociais de comunicação. Estamos vivenciando uma revolução "ciberespacial" nas palavras de Luís Alberto Warat, para quem os fins do saber estão mudando, para atender a outro tipo de sociedade, onde as antigas concepções do tempo desaparecem, onde o espaço se decompõe sem fronteiras. "É a revolução total dos costumes, dos espaços sócio-políticos, e dos trânsitos e vínculos da subjetividade" ${ }^{25}$.

A infraestrutura tecnológica contemporânea tem possibilitado que a espécie humana se encontre praticamente "cara a cara" através dos territórios (janelas) dos ciberespaços. As distâncias estão perdendo relevância nessa nova era da globalização tecnológica da comunicação. Os acontecimentos parecem durar pouco tempo, considerando a simultaneidade da transmissão dos fatos. Graças ao progresso da informação, afirmava Milton Santos ${ }^{55}$ "[...] o mundo fica mais perto de cada um, não importa onde esteja. O outro, isto é, o resto da humanidade, parece estar próximo".

Na nova era da comunicação, "criam-se para todos a certeza e, logo depois, a consciência de ser mundo e de estar no mundo, mesmo se ainda não o alcançamos em plenitude material ou intelectual" ${ }^{\prime \prime 6}$. A dialética da interconexão enriquece o cotidiano da vida de cada um pela experiência própria e pela do vizinho. Lembrando que o vizinho não é necessariamente aquele que reside ao lado da nossa casa, mas aquele que se encontra em diversos lugares, seja esses locais, nacionais ou transnacionais, ou ainda nas janelas da comunicação virtual.

Os humanos estão cada vez mais unidos e estão se convertendo em partes de um sistema global, em "cidadãos" de um mundo que está se transformando numa grande praça pública universal ${ }^{57}$. Nas condições atuais, o cidadão do lugar pretende se instalar como cidadão do mundo. "Estamos descobrindo o sentido de nossa presença no planeta, pode-se dizer que uma história universal, verdadeiramente humana está finalmente começando" ${ }^{\prime 58}$.

José Eduardo Faria em 2004 sugeriu que "[...] quanto mais disponíveis e sofisticadas são as formas de vinculação eletrônica entre as pessoas, mais

\footnotetext{
${ }^{54}$ WARAT, Luis Alberto. Territórios Desconhecidos: a procura surrealista pelos lugares do abandono do sentido e da reconstrução da subjetividade. Florianópolis: Fundação Boiteux, 2004. p. 266.

${ }^{55}$ SANTOS, Milton. Por uma outra Globalização. São Paulo: Record, 2001. p. 172.

${ }^{56}$ SANTOS, Milton. Por uma outra Globalização. São Paulo: Record, 2001. p. 172.

${ }^{57}$ RIFKIN, Jeremy. La Civilización Empática. La Carrera hacia una Conciencia Global en un Mundo en Crisis. Tradução de Genis Sánchez Barverán e Vanessa Casanova. 1. ed., Mardri: Paidós, 2010. p. 411.

${ }^{58}$ SANTOS, Milton. Por uma outra Globalização. São Paulo: Record, 2001. p. 174.
} 
amplas acabam sendo as possibilidades de 'encontros sociais'”. Esses novos encontros sociais não ocorrem nas tradicionais e modernas estruturas públicas constitutivas da cidadania nacional, ocorrem no espaço virtual "[...] entre quem jamais se encontrou ao menos uma vez frente a frente, entre quem jamais se falou pessoalmente; quanto mais as relações por meio de redes informatizadas se sobrepõem, mais se desterritorializa os universos simbólicos" ${ }^{\prime 59}$.

A mutação tecnológica se reproduz com a emergência das técnicas da comunicação e informação, as quais ao contrário das técnicas mecanicistas modernas são constitucionalmente divisíveis, flexíveis e dóceis, adaptáveis a todos os meios culturais e de conhecimento, rompendo com os paradigmas modernos da ciência, trazendo consigo a ideia de revisão, de encontro com a sensibilidade, que "permite a sinergia dos elementos 'arcaicos', tradicionais, e da tecnologia de ponta"60.

Como sugere Michel Mafessoli na obra A transfiguração do político: a tribalização do mundo redescobre-se a multidimensionalidade do conhecimento que deve encontrar sua unicidade na pessoa humana. "O conhecimento envolve razão e sensibilidade, corpo e espírito, teoria e práxis, ordem e desordem, caos e organização" ${ }^{\text {"61. }}$. Essa nova técnica da comunicação ainda está subordinada aos interesses dos grandes capitais. Mas, quando sua utilização for democratizada, essas técnicas "doces" estarão ao serviço do homem - que denomina-se como a possibilidade da democracia assimétrica transnacional ${ }^{62}$.

\section{OS NOVOS AMBIENTES ASSIMÉTRICOS TRANSCIONALIZADOS}

Na linha adotada por Paulo Roberto Almeida ${ }^{63}$ professor doutor e diplomata Brasileiro, no artigo $\mathrm{O}$ Poder e a Glória: a questão das assimetrias no sistema internacional, a noção pura de assimetria se refere a diferenças estruturais, que podem se naturais ou adquirias.

Em tempos de globalização o conceito de assimetria geralmente está associado a conotações negativas, que se traduzem nos diferenciais de poder políticos (em termos de estrutura política interna dos Estados e internacional) sociais (garantias de direitos sociais), culturais (língua, representações artísticas) e econômicas (de mercado e capital).

\footnotetext{
${ }^{59}$ FARIA, José Eduardo. O Direito na Economia Globalizada. São Paulo: Malheiros, 2004. p. 29.

60 MAFFESOLI, Michel. A Transfiguração do Político: a tribalização do mundo. Porto Alegre: Sulinas, 1997. p. 13.

${ }^{61}$ DIAS, Maria da Graça dos Santos. Direito e Pós-modernidade. In: DIAS, Maria da Graça dos Santos; MELLO, Osvaldo Ferreira de; SILVA, Moacyr Motta da. Política Jurídica e Pós-modernidade. Florianópolis: Conceito Editorial, 2009. p. 16.

${ }^{62}$ CRUZ, Paulo Márcio; REAL FERRER, Gabriel. Os Novos Cenários Transnacionais e a Democracia Assimétrica. Revista Direito e Justiça, no 17, nov. 2011. Disponível em: <http://br.vlex. $\mathrm{com} / \mathrm{vid} / \mathrm{cenarios}$-transnacionais-assimetrica-418616214>.

${ }^{63}$ ALMEIDA, Paulo Roberto. O Poder e a Glória: a questão das assimetrias no sistema internacional. Revista Espaço Acadêmico, $\mathrm{n}^{\circ}$ 49, jun. 2005. Disponível em: <http://www.espacoacademico. com.br/049/49pra.htm>.
} 
Ao longo de todo período histórico [da evolução da Humanidade e do Estado], houve sempre uma grande assimetria de poder. Esta assimetria deu-se no domínio econômico, deu-se no domínio político, deu-se no domínio cultural. Obviamente, ela assumiu diferentes formas: a atual, por exemplo, não assume a forma de colonialismo, mas assume outras formas ${ }^{64}$.

As assimetrias políticas e de poder costumam dividir os países em um grupo restrito de nações poderosas (chamadas superpotências), em um grupo intermediário de potências médias (que poderiam ser chamados de emergentes) e o resto dos países sem grande peso na comunidade internacional ${ }^{65}$.

Desse ponto de vista, quando se pensa em assimetria de poder, pensa-se naquele grupo de nações poderosas no plano militar, no domínio econômico e tecnológico, sobretudo, na capacidade financeira de prestar ajuda ao desenvolvimento, e de tomar iniciativas no plano multilateral.

Gilberto Dupas no capítulo Assimetrias e impasses na nova lógica do poder global afirma que profundas são as assimetrias entre os poderes que exercem os principais atores econômicos, políticos e sociais sobre a nova ordem global. As novas assimetrias estabelecidas pelas globalizações provocam instabilidades, impasses e desequilíbrio na formulação de modelos consistentes de equilíbrio e governabilidade sistêmica ${ }^{66}$.

De maneira esquemática, podem-se agrupar os novos atores do poder no jogo global em torno de três áreas principais: do capital (atores da economia global, incluindo corporações, sistema financeiro, associações empresariais, acionista), da sociedade civil (indivíduos e organizações sociais não governamentais) e por fim, a área do Estado (Executivo, legislativo, Judiciário, partidos políticos e instituições internacionais). Esse novo quadro de atores e poderes questiona a autonomia dos Estados Nacionais e intensifica as assimetrias de existentes entre eles ${ }^{67}$.

As organizações internacionais, empresas transnacionais e organizações não governamentais, podem ser exemplos de instituições públicas ou privadas que atuam nos novos ambientes assimétricos globalizados. Esses novos atores ganharam poder e, se tornaram atores da nova ordem global. Isso não significa que os Estados não continuam sendo atores, o são, e por certo, em algumas pautas (questões), atores centrais.

\footnotetext{
${ }^{64}$ SANTOS, Boaventura de Sousa. Dilemas do nosso Tempo: globalização, multiculturalismo e conhecimento (entrevista com Boaventura de Sousa Santos). Currículo sem Fronteiras, v. 3, $\mathrm{n}^{\circ} 2$, pp. 5-23, jul./dez. 2003. Disponível em: <http://www.ufpel.edu.br/fae/ppge/arquivos/File/alvaro_ hypolito/boaventura_santos.pdf>. Acesso em: 29 jun. 2013.

${ }^{65}$ ALMEIDA, Paulo Roberto. O Poder e a Glória: a questão das assimetrias no sistema internacional. Revista Espaço Acadêmico, $\mathrm{n}^{\circ}$ 49, jun. 2005. Disponível em: <http://www.espacoacademico. com.br/049/49pra.htm>.

${ }^{66}$ DUPAS, Gilberto. Atores e Poderes na Nova Ordem Global: Assimetrias, instabilidades e imperativos da legitimação. São Paulo: UNESP, 2005.

67 DUPAS, Gilberto. Atores e Poderes na Nova Ordem Global: Assimetrias, instabilidades e imperativos da legitimação. São Paulo: UNESP, 2005.
} 
Mas agora, o Estado se caracteriza como um ator que age movido, exclusivamente, pelo seu caráter racional. Como antes entredito, o Estado surgiu na lógica mecânica, instrumental e procedimentalista moderna, de tal modo, que o Estado age de acordo com os interesses, oportunidade e limitações do sistema interdependente, definindo a sua agenda de estratégias a partir da delimitação das relações, sobretudo, econômicas, o que permite determinar diferenciais (assimetrias) de poder entre os atores.

Os processos históricos vivenciados com o advento da globalização, colocaram em questão os novos atores transnacionais (crenças, os valores, as práticas erigidas e consagradas na modernidade iluminista) atingindo principalmente os espaços (esferas) de convivência e existência humana: a política, a economia e a cultura, expressando novas significações do pensamento, da razão, da liberdade, da comunicação. Os ambientes brotados desses processos não são simétricos, antes se configuram nas assimetrias.

Como antes expressado, as assimetrias trazem implicitamente a ideia de diferenças que podem resultar em vulnerabilidades. Portanto, torna-se fundamental saber quais são as diferenças e saber quais diferenças será relevante, pois um amplo emprego do termo pode reduzi-lo a sua utilidade analítica $^{68}$.

No contexto dos novos ambientes globalizados (registra-se que, esses podem representar também um contexto de renovado impulso integrador em nível transnacional), a questão das assimetrias (entendidas como diferenças estruturais e políticas entre países originadas de dimensão econômica, posição geográfica, dotação de fatores, acesso à infraestrutura regional, qualidade institucional e nível de desenvolvimento) subsiste como desafio fundamental a ser enfrentado.

Roberto José Moreira em 2003 no texto Cultura, política e o rural na contemporaneidade, argumenta que as "[...] relações de poderes assimétricos, mesmo que exercidos em assimetrias hegemônicas, democraticamente construídas, produzem identidades hegemônicas e subalternas, reproduzindo ou reconstruindo as hierarquias sociais herdadas" 69 .

Nesse sentido, pode-se delinear que será fundamental na transnacionalidade a redução das assimetrias estruturais, que se originam de discrepâncias globalizadas quanto à dimensão econômica, social, ambiental, posição geográfica, acesso a informação e tecnologias, e a redução das assimetrias políticas, que resultam da falta de convergência e a coordenação entre as políticas.

\footnotetext{
${ }^{68}$ WILSON, P. Asymmetric Threats, in Strategic Assessment 1998 Engaging Power for Peace National Defense University. Disponível em: <http://www.ndu.edu/inss/Strategic\%20Assessments/ sa98/sa98ch11.htm>. Acesso: em 20 fev. 2014.

${ }^{69}$ MOREIRA, Roberto José. Cultura, Política e o Rural na Contemporaneidade. Estudos Sociedade e Agricultura, $n^{\circ}$ 20, 113-143, abr. 2003.
} 


\section{CONSIDERAÇÕES FINAIS}

A intensificação dos processos de regionalização e globalização, particularmente depois da Segunda Guerra Mundial, mais especificamente depois do quebra do contra ponto socialista, contribuiu simultaneamente para a expansão das responsabilidades funcionais do Estado e ao mesmo tempo para a erosão de suas capacidades para atender sozinho, de forma efetiva, as demandas colocadas por aqueles fenômenos.

A relativização do conceito tradicional de soberania, como poder supremo do Estado em face fenômeno da globalização, da transnacionalização da economia mundial e a consequente interdependência dos Estados teria levado o Estado Constitucional Moderno ao fenecimento, questionando-se algumas suas funções, sobretudo, de proteção dos direitos sociais, ambientais e econômicos.

Os novos ambientes transnacionais brotados em parte da relativização do poder soberano do Estado podem ser caracterizados por uma complexa teia de relações, políticas, socias, econômicas e jurídicas, no qual emergem novos atores, interesses e conflitos, que demandam respostas eficazes.

No contexto dos novos ambientes assimétricos globalizados (registra-se que, esses podem representar também um contexto de renovado impulso integrador em nível transnacional), a questão das assimetrias subsiste como desafio fundamental a ser enfrentado pelo Estado e pela necessária regulação transnacional.

Buscou-se no decorrer do artigo expor que os atores e poderes transnacionais que conseguem fugir do controle e da autoridade dos Estados, das normas de direito nacional, internacional e supranacional são peças importantes da nova estrutura de governança e regulação transnacional, contudo, será necessária a limitação de atuação desses atores e poderes transnacionais para que não seja identificada a ideia de "governança sem governo", na qual a autoridade estaria cada vez mais sendo transferida dos Estados territoriais para as entidades não territoriais.

Como entredito, a formação de novos poderes nos espaços transnacionais possibilitados pela globalização estão sem regulamentação, assim, requer-se a politização da discussão sobre a limitação desses tipos de poder e, por conseguinte o estabelecimento de novos direitos (transnacionais) destinados a regulá-los e limitá-los.

Considera-se que os Estados estão inseridos em novos ambientes assimétricos (poder, da comunicação, econômicos) e em várias formas não convencionais de violências, concorrência econômica, circulação de bens, pessoas, serviços, atos terroristas, ataques aos sistemas informatizados, sabotagem, situações econômicas, sociais e culturais predominantemente assimétricas que solaparam de maneira irreversível as bases teóricas do Estado Constitucional Moderno e do sistema democrático representativo. 
Maiormente, a perda de centralidade institucional e da eficácia reguladora dos Estados Constitucionais Moderno não foi compensada (por hora) pelo aumento de poder de quaisquer instâncias transnacionais, no entanto, ainda que de forma assimétrica está emergindo uma nova cultura direcionada para a resolução solidária dos problemas transnacionais decorrentes da complexidade dos problemas atuais e dos novos ambientes assimétricos.

\section{REFERÊNCIAS BIBLIOGRÁFICAS}

ALMEIDA, Paulo Roberto. O Poder e a Glória: a questão das assimetrias no sistema internacional. Revista Espaço Acadêmico, no 49, jun. 2005. Disponível em: <http://www.espacoacademico.com.br/049/49pra.htm>.

ARISTÓTELES. Política. Tradução de Mário da Gama Kury. Brasília: UnB, 1985.

BASTOS, Celso Ribeiro. Teoria do Estado e Ciência Política. 5. ed., São Paulo: Celso Bastos, 2002.

BECK, Ulrich. A Sociedade Global de Risco. Uma Discussão entre Ulrich Beck e Danilo Zolo. Trad. port.: Selvino J. Assmann. Disponível em: <SWIF (http://lgxserver.uniba.it) Web italiano para a Filosofia - Copyrigt 1997-1998>.

BECK, Ulrich. O que é globalização? equívocos do globalismo: resposta à globalização. Tradução de André Carone. São Paulo: Paz e Terra, 1999.

BELLO FILHO, Ney de Barro. Pressupostos Sociológicos e Dogmáticos da Fundamentalidade do Direito ao Ambiente Sadio e Ecologicamente Equilibrado. Tese de Doutorado. Universidade Federal de Santa Catarina. 2006.

BONAVIDES, Paulo. Ciência Política. 12. ed., São Paulo: Malheiros, 2006.

BONDIN, Jean. Os Seis Livros da República. Tradução, Introdução e Notas José Carlos Orsi Morel. Revisão Técnica da Tradução José Ignacio Coelho Mendes Neto. São Paulo: ÍCONE, 2011.

CRUZ, Paulo Márcio. Da Soberania a Transnacionalidade: democracia, direito e estado no século XXI. Seleção e organização dos capítulos Emanuela Cristina Andrade Lacerda. Itajaí: UNIVALI, 2011.

CRUZ, Paulo Márcio; REAL FERRER, Gabriel. Os Novos Cenários Transnacionais e a Democracia Assimétrica. Revista Direito e Justiça, no 17, nov. 2011. Disponível em: $<$ http://br.vlex.com/vid/cenarios-transnacionais-assimetrica-418616214>.

DALLARI, Dalmo de Abreu. Elementos da Teoria Geral do Estado. 25. ed., São Paulo: Saraiva, 2005.

DIAS, Maria da Graça dos Santos. Direito e Pós-modernidade. In: DIAS, Maria da Graça dos Santos; MELLO, Osvaldo Ferreira de; SILVA, Moacyr Motta da. Política Jurídica e Pós-modernidade. Florianópolis: Conceito Editorial, 2009.

DUPAS, Gilberto. Atores e Poderes na Nova Ordem Global: Assimetrias, instabilidades e imperativos da legitimação. São Paulo: UNESP, 2005.

FARIA, José Eduardo. O Direito na Economia Globalizada. São Paulo: Malheiros, 2004. GIDDENS, Anthony. As Consequências da Modernidade. Tradução de Raul Filker. São Paulo: Unesp, 1991.

HABERMAS, Jürgen. A Constelação Pós-nacional: ensaios políticos. Tradução de Márcio Seligmann Silva. São Paulo: Littera Mundi, 2001. 
HABERMAS, Jürgen. A Inclusão do Outro: estudos de teoria política. Tradução de Goerge Sperber e Paulo Astor Soethe. São Paulo: Loyola, 2002.

HELD, David. La Democracia y el Orden Global: Del Estado moderno al gobierno cosmopolita. Traducción de Sebastián Mazzuca. Barcelona: Paidós, 2002.

HOBBES, Thomas. Leviatã. In: Coleção Os Pensadores, São Paulo: Nova Cultural, 1988.

HÖFFE, Otfried. A Democracia no Mundo de Hoje. Tradução de Tito Lívio Romão, revisão da tradução de Luz Moreira. São Paulo: Martins Fontes, 2005.

IHERING, Rudolf Von. A Luta pelo Direito. São Paulo: Rideel, 2005.

KELSEN, Hans. A Democracia. Tradução de Ivone Castilho Benedetti, Jefferson Luiz Camargo, Marcelo Brandão Cipolla e Vera Barkow. São Paulo: Martins Fontes, 2000.

LIPOVESTSKY, Gilles; SERROY, Jean. A Cultura Mundo: resposta a uma sociedade desorientada. Tradução de Maria Lúcia Machado. São Paulo: Companhia das Letras, 2011.

LUHMANN, Niklas. A Realidade dos Meios de Comunicação. São Paulo: Paulus, 2005. . DE GIORGI, Rafaelle. Teoría de la Sociedad. México: Universidad de Guadalajara/Univesidad Iberoamericana/ITESO, 1993.

MACCHIAVELLI, Niccolò. O Príncipe: comentários de Napoleão Bonaparte e Cristina da Suécia. Tradução e revisão de Ana Paula Pessoa. São Paulo: Jardim dos Livros, 2007.

MAFFESOLI, Michel. A Transfiguração do Político: a tribalização do mundo. Porto Alegre: Sulinas, 1997.

MOREIRA, Roberto José. Cultura, Política e o Rural na Contemporaneidade. Estudos Sociedade e Agricultura, n 20, 113-143, abr. 2003.

MÜLLER, Friedrich. Que Grau de Exclusão Social ainda pode ser Tolerado por um Sistema Democrático?. Porto Alegre: Unidade Editorial, 2000.

OST, Franções. Mondialisation, Globalisation, Universalisation: s'arracher, encorre et toujours, à l'etat de nature. In: MORAND, Charles-Albert (org). Bruxelles: Bruylant, 2001.

PAUPÉRIO, Machado. O Conceito Polêmico de Soberania. 2. ed., Rio de Janeiro: Freitas Bastos, 1958.

RIFKIN, Jeremy. La Civilización Empática. La Carrera hacia una Conciencia Global en un Mundo en Crisis. Tradução de Genis Sánchez Barverán e Vanessa Casanova. 1. ed., Mardri: Paidós, 2010.

ROUSSEAU, Jean-Jacques. O Contrato Social. Tradução de Antônio de P. Machado. Rio de Janeiro: Ediouro, 1995.

SANTOS, Boaventura de Sousa (org.) A Globalização e as Ciências Sociais. 2. ed., São Paulo: Cortez, 2002.

. Dilemas do Nosso Tempo: globalização, multiculturalismo e conhecimento (entrevista com Boaventura de Sousa Santos). Currículo sem Fronteiras, v. 3, $\mathrm{n}^{\circ} 2$, pp. 5-23, jul./dez. 2003. Disponível em: <http://www.ufpel.edu.br/fae/ppge/arquivos/ File/alvaro_hypolito/boaventura_santos.pdf>. Acesso em: 29 jun. 2013.

SANTOS, Milton. Por uma outra Globalização. São Paulo: Record, 2001.

STELZER, Joana. O Fenômeno da Transnacionalização de Dimensão Jurídica. In: CRUZ, Paulo Márcio; STELZER, Joana. (orgs.). Direito de Transnacionalidade. Curitiba: Juruá, 2009. 
TEUBNER, Gunther. A Bukowina Global sobre a Emergência de um Pluralismo Jurídico Transnacional. Impulso. Piracicaba, 14(33): 9-31, 2003, p. 13. Disponível em: $<$ http://www.unimep.br/phpg/editora/revistaspdf/imp33art01.pdf>. Acesso em: 02 jan. 2014. WARAT, Luis Alberto. Territórios Desconhecidos: a procura surrealista pelos lugares do abandono do sentido e da reconstrução da subjetividade. Florianópolis: Fundação Boiteux, 2004.

WEFFORT, Francisco C. (org.). Os Clássicos da Política. V. 1, São Paulo: Ed. Ática, 1989. WILSON, P. Asymmetric Threats, in Strategic Assessment 1998 Engaging Power for Peace NATIONAL DEFENSE UNIVERSITY. Disponível em: <http://www.ndu.edu/inss/ Strategic\%20Assessments/sa98/sa98ch11.htm>. Acesso em: 20 fev. 2014.

ZAGREBELSKY, Gustavo. El Derecho Dúctil: ley, derechos, justicia. 6. ed., Traducción de Marina Gascón. Madri: Trotta, 2005. 